\title{
Shape memory effect and superelasticity of Ni-free Ti-Nb-based alloys
}

\author{
Zhengcun Zhou ${ }^{1 \mathrm{a}}$,Dewen $\mathrm{Guo}^{2 \mathrm{~b}}$, Jie $\mathrm{Du}^{1 \mathrm{c}}$, Suyi $\mathrm{Gu}^{1 \mathrm{~d}}$ \\ ${ }^{1}$ School of Mechanical and Electronic Engineering, Suzhou Vocational University, Suzhou, 215104, \\ China) \\ ${ }^{2}$ Anhui Guozhen Environmental Protection Science and Technology Joint Stock Co. Ltd.,Hefei, \\ 230088, China) \\ azzc@jssvc.edu.cn, b2762287528@qq.com, duj@jssvc.edu.cn, dgsy@jssvc.edu.cn
}

Keywords: Ni-free Ti-Nb-based alloys, shape memory effect, superelasticity

Abstract. Ni-Free Ti-Nb-based alloys have potential application as non-toxic shape memory and superelastic alloys. The shape memory behavior and superelasticity of free-Ni Ti-Nb-based alloys were described and discussed in this paper. It was shown that the excellent shape memory behavior and superelasticity can be obtained by a reasonable chemical composition and heat treatments. $\beta$-Ti-Nb alloys undergo a martensitic transformation when the alloys are rapidly cooled from the $\beta$ phase region at high temperatures. This transformation produces $\alpha$ or $\alpha$ " martensite. The transformation from $\beta$ phase to $\alpha$ " martensite is a thermoelastic one and thereby produces shape memory effect and superelasticity. The start temperature of martensitic transformation (Ms) decreases with increasing $\mathrm{Nb}$ contents. $\mathrm{Nb}$ contents are located between 22-26 (at.\%) among the reported $\mathrm{Ti}-\mathrm{Nb}$ alloys since the superelasticity at room temperature exists when the Ti-Nb alloys have the compositions of $22-26 \mathrm{at} . \% \mathrm{Nb}$. The addition of the elements such as $\mathrm{Zr}, \mathrm{Sn}, \mathrm{O}$ and $\mathrm{Al}$ has influences on the shape memory effect and superelasticity of Ti-Nb alloys, which decreases Ms and increases superelasticity. Ti-22Nb-4Zr (at.\%) and $\mathrm{Ti}-24 \mathrm{Nb}-3 \mathrm{Al}$ (at.\%) possesses large recovery strain. The maximum recovery strain is $4.3 \%$ for the former and $4.7 \%$ for the latter, respectively.

\section{Introduction}

It is well known that Ti-Ni shape memory alloys have been successfully applied as biomedical materials, such as orthodontic archwires, bone plates and stents, owing to their superior shape memory properties, superelasticity and corrosion resistance. However, the issues of the hypersensitivity and toxicity of $\mathrm{Ni}$ have been reported, which stimulates the development of Ni-free Ti-based alloys [1-7]. Therefore, Ni-free $\beta$-Ti-based (Ti-Nb, Ti-Ta, Ti-Mo, Ti-Zr, et al) alloys, especially $\mathrm{Ti}-\mathrm{Nb}$ alloys have been paid much attention and have been developed as biomedical shape memory and superelastic alloys [8-19]. In this paper, shape memory effect and superelasticity of Ni-free Ti-Nb-based alloys are described and discussed.

\section{Shape memory effect and superelasticity of Ni-free Ti-Nb-based alloys}

It was first reported by Baker [20] that a change of $\alpha$ " (orthorhombic martensite) to $\beta$ (disordered body-centered cubic) resulted in a shape memory effect in Ti-35 (wt.\%) Nb alloy. Although he reported that aging of short durations at 573-773 $\mathrm{K}$ improved shape memory effect due to the precipitation of $\omega$ phase, he did not demonstrate the superelasticity of the Ti-Nb alloy. Kim et al [12-13] reported that the Ti-(22-27) (at.\%)Nb alloys exhibited shape memory effect and superelastic behavior at room temperature. The transformation strain and transformation temperature linearly 
decreased with increasing $\mathrm{Nb}$ content. The low critical stress for slip deformation resulted in only a small superelastic strain in solution-treated Ti-Nb binary alloys. Fine and dense $\omega$ precipitates formed during aging in the temperature range between 573 and $673 \mathrm{~K}$ were effective in increasing the critical stress for slip deformation in a Ti-26 (at.\%) $\mathrm{Nb}$ alloy. The higher critical stress for slip deformation resulted in a larger recovery strain and stable superelasticity. Excellent superelasticity was obtained by annealing at $873 \mathrm{~K}$ for $600 \mathrm{~s}$ followed by aging at $573 \mathrm{~K}$ due to the combined effect of work hardening and age hardening. Tahara et al [21] investigated the effect of cyclic deformation on superelasticity for a Ti-26 (at.\%) $\mathrm{Nb}$ alloy. Loading and unloading tensile tests with a constant maximum applied strain of $2.5 \%$ were carried out until the 500th cycle. The critical stress for inducing the martensitic transformation and superelastic strain decreased, while the accumulated residual strain increased with increasing number of cycles. The increase in the residual strain during cyclic deformation was due mainly to $\alpha$ " martensite phase stabilization. Both the residual strain and the residual $\alpha$ " martensite phase increased with increasing number of cycles. The stability of superelasticity was improved, i.e. the residual strain decreased and the superelastic strain increased by intermediate-temperature annealing and/or aging. The specimen annealed at $873 \mathrm{~K}$ for $0.6 \mathrm{ks}$ followed by aging at $573 \mathrm{~K}$ for $3.6 \mathrm{ks}$ exhibited the most stabilized superelasticity, owing to the combination effect of work hardening and fine $\omega$-phase precipitation. Kim et al [22] investigated the effect of alloying on microstructure and elastic modulus for ternary Ti-Nb-Si alloys. It was shown that $\mathrm{Si}$ has an effective role in suppressing the occurrence of $\omega$-phase and decreasing the elastic modulus in a meta-stable $\beta$-phase region. Ping et al [23] investigated shape memory behavior of a Ti-30Nb-3Pd (wt.\%) alloy. This alloy possesses high temperature shape memory behavior, which has a $\mathrm{M}_{\mathrm{s}} \sim 561 \mathrm{~K}, \mathrm{M}_{\mathrm{f}} \sim 446 \mathrm{~K}, \mathrm{~A}_{\mathrm{s}} \sim 678 \mathrm{~K}$ and $\mathrm{A}_{\mathrm{f}} \sim 772 \mathrm{~K}$ after being deformed and solution treated at 973-1173 K, followed by water-quenching. A strain limit for $100 \%$ recovery was measured around $2 \%$ after aging at $873 \mathrm{~K}$ for $20 \mathrm{~min}$. Hao et al [24] investigated the effect of $\mathrm{Zr}$ and Sn on Young's modulus and of Ti-Nb alloys with the compositions of (20-26) Nb, (2-8) $\mathrm{Zr}$ and (3.5-11.5)Sn (wt.\%). The martensitic start temperature of the $\alpha$ "is depressed by $\mathrm{Zr}$ and $\mathrm{Sn}$ additions. Of the studied alloys, Ti-24Nb-4Zr-7.5Sn (wt.\%) with single $\beta$ microstructure has the lowest Young's modulus of $52 \mathrm{GPa}$ and recoverable elastic strain of about $2 \%$ at room temperature after cyclic strain, which has good superelasticity. Kim et al [25] investigated effect of thermo-mechanical treatment on mechanical properties and shape memory behavior of Ti-(26-28) (at.\%) $\mathrm{Nb}$ alloys. The superelastic behavior was observed in the temperature ranges between 293 and $313 \mathrm{~K}$ in the Ti-26 (at.\%) Nb, 193 and $313 \mathrm{~K}$ in the Ti-27 (at.\%) $\mathrm{Nb}$ and 163 and $233 \mathrm{~K}$ in the Ti-28 (at.\%) $\mathrm{Nb}$ alloys, respectively. However, perfect superelastic behavior with a strain larger than $2 \%$ could not be obtained at room temperature because of the low critical stress for slip deformation in the solution treated alloys. Ultimate tensile strength decreased and fracture strain increased with increasing annealing temperature. The low temperature annealing at $873 \mathrm{~K}$ stabilized the superelasticity in the Ti-(26-28) (at.\%) $\mathrm{Nb}$ alloys. The aging treatment at $573 \mathrm{~K}$ after annealing at $873 \mathrm{~K}$ increased both of the tensile strength and the critical stress for inducing the martensitic transformation due to the formation of thermal $\omega$ phase in the Ti-(26-28) (at.\%)Nb alloys. However, the elongation decreased with increasing aging time. Perfect superelastic behavior was obtained with the strain up to $3 \%$ by annealing at $873 \mathrm{~K}$ followed by subsequent aging at $573 \mathrm{~K}$ for $3.6 \mathrm{ks}$ in the Ti-26 (at.\%) Nb alloy. $\mathrm{Kim}$ et al [26] investigated shape memory characteristics of $\mathrm{Ti}-22 \mathrm{Nb}-(2-8) \mathrm{Zr}(\mathrm{at} . \%)$ biomedical alloys. All the alloys were solution-treated at $1173 \mathrm{~K}$ for $1.8 \mathrm{ks}$ after being cold-rolled by a reduction up to $95 \%$ in thickness at room temperature. The alloys subjected to the solution treatment exhibited large elongations ranging between 28 and 40\%. The martensitic transformation temperature decreased by $38 \mathrm{~K}$ with 1 at.\% increase of $\mathrm{Zr}$ content. The maximum recovered strain 
of $4.3 \%$ was obtained in the $\mathrm{Ti}-22 \mathrm{Nb}-4 \mathrm{Zr}$ (at.\%) alloy. $\mathrm{Ti}-22 \mathrm{Nb}-(2-4) \mathrm{Zr}$ (at.\%) and $\mathrm{Ti}-22 \mathrm{Nb}-6 \mathrm{Zr}$ (at.\%) alloys exhibited stable shape memory effect and superelastic behavior at room temperature, respectively. Lee et al [27] investigated the structure-property relaxation of cast Ti-Nb alloys. The c. p. Ti (commercial pure Ti) has a hexagonal $\alpha$ phase with a lath type morphology. The alloys are primarily containing 15 (wt.\%) $\mathrm{Nb}$ or less $\mathrm{Nb}$ are dominated by a hexagonal $\alpha$ phase with an acicular, marensitic structure. When containing 17.5-25 (wt.\%) $\mathrm{Nb}$, the alloys are primarily comprised of an orthorhombic $\alpha$ " phase. With 27.5 (wt.\%) $\mathrm{Nb}$, metastable $\beta$ phase starts to be retained. With $\mathrm{Nb}$ contents higher than 30 (wt.\%) $\mathrm{Nb}$, the equi-axed $\beta$ phase is almost entirely retained. Small amounts of $\omega$ phase are detected in alloys containing 27.5 and 30 (wt.\%) $\mathrm{Nb}$. Among all present alloys, Ti-10 (wt.\%) $\mathrm{Nb}$ and Ti-27.5 (wt.\%) $\mathrm{Nb}$ exhibit the highest strengths, while the $\alpha$ "-dominated (17.5 (wt.\%) and 20 (wt.\%) $\mathrm{Nb}$ ) and $\beta$-dominated (>30 (wt.\%) Nb) alloys have the lowest moduli. All Ti-Nb alloys show excellent corrosion resistance in Hank's solution at $37{ }^{\circ} \mathrm{C}$. From the present data, the microhardness, bending strength and modulus of the various phases in $\mathrm{Ti}-\mathrm{Nb}$ alloys are compared and tentatively summarized as follows: Microhardness and bending strength: $\omega>\alpha^{\prime}>\alpha^{\prime \prime}>\beta>\alpha$ (c.p. Ti), bending modulus: $\omega>\alpha$ (c.p. Ti) $>\alpha^{\prime}>\alpha^{\prime \prime}>\beta$. Mantani et al [28] investigated effect of ageing on internal friction and elastic modulus of Ti-Nb alloys. Four types of alloys, which had niobium concentrations of 25, 30, 35, and 40 (wt.\%), were used. These alloys were solution-treated at $1223 \mathrm{~K}$, and aged at 423, 573, and $723 \mathrm{~K}$. Although the highest Young's modulus of the quenched specimens was observed in the $\alpha$ " $\beta$ duplex structure of $\mathrm{T}-30(\mathrm{wt} . \%) \mathrm{Nb}$ and not the martensite structure of $\mathrm{T}-25(\mathrm{wt} . \%) \mathrm{Nb}$, it decreased with the amount of $\alpha$ " martensite in other alloys. The internal friction of the quenched specimen decreased as the amount of the $\beta$ phase increased. The internal friction increased, but Young's modulus decreased during the processes of $\alpha " \rightarrow \beta$ reverse transformation and $\alpha$ precipitation during the ageing treatments. On the other hand, the internal friction decreased, but Young's modulus increased during the process of aged $\omega$ precipitation. In particular, the decreased internal friction of the $\alpha$ " martensite structure of Ti-25 (wt.\%) $\mathrm{Nb}$ alloys aged at $723 \mathrm{~K}$ and the changes in both the internal friction and Young's modulus during the process of aged $\omega$ precipitation of the $\alpha "+\beta$ duplex structure were remarkable. Matlakhova et al [29] investigated influence of temperature on the properties and phase transformations in Ti-Nb alloys with 2 (wt.\%) Al and 15-40 Nb (wt.\%). Depending on the relative amount of $\mathrm{Nb}$, the quenching process of Ti-Nb-2 (wt.\%) Al alloys, from temperatures corresponding to the stable $\beta$ phase, will produce distinct structures. After heating, the initial metastable structure [ $\alpha^{\prime}\left(\right.$ up to $\left(15\right.$ wt. \%) Nb), $\alpha^{\prime}+\alpha^{\prime \prime}\left(15\right.$ to 24 (wt. \%) Nb), $\alpha^{\prime}\left(\alpha^{\prime \prime}\right)+\omega$ (24 to 30 (wt. \%) Nb), $\alpha^{\prime}\left(\alpha^{\prime \prime}\right)+\beta$ (30 to 35 (wt. \%) Nb), $\alpha " \beta(35$ to 40 (wt. \%) $\mathrm{Nb}$ ) or $\beta$ (> 40 (wt. \%) $\mathrm{Nb}$ )] undergoes transformations towards a stable condition. The moduli, $\mathrm{E}$ and $\mathrm{G}$, goes through a minimum at a critical value in temperature that could be attributed to lattice softening before $\alpha^{\prime}\left(\alpha^{\prime \prime}\right)$ to $\beta$ transformation. Above this critical point, the $\beta$ phase becomes more stable and stiffer the higher the temperature. In the case of alloys with no initial $\beta$ phase, but only $\alpha^{\prime}\left(\alpha^{\prime \prime}\right)$ martensite, up to 30 (wt.\%) $\mathrm{Nb}$, stable $\beta$ transforms above $500{ }^{\circ} \mathrm{C}$. Consequently, the minimum in $\mathrm{E}$ and $\mathrm{G}$ occurs at these relatively high temperatures. By contrast, alloys with initial $\alpha^{\prime}\left(\alpha^{\prime \prime}\right)+\beta$ or single metastable $\beta$, will suffer reverse martensitic transformation and/or $\beta$ decomposition at significantly lower temperature. Therefore, the minimum in $\mathrm{E}$ and $\mathrm{G}$ occurs at temperatures not greater than $200{ }^{\circ} \mathrm{C}$. Chai et al [30] investigated self-accommodation morphology of the $\alpha$ " martensites in Ti-Nb shape memory alloys with content ranging from 20-40 (at.\%). Hollow and solid triangular morphologies consisting of three $\alpha$ " variants were found to be the $\alpha$ " self-accommodation morphologies. Kim et al [31] investigated texture and shape memory behavior of Ti-22Nb-6Ta (at.\%) alloy. A well developed $\{001\}<1 \overline{1} 0>$ texture was obtained in the as-rolled specimen and after heat treatment at 
$873 \mathrm{~K}$ for $600 \mathrm{~s}$. A recrystallization texture of $\{112\}<1 \overline{1} 0>$ was developed after heat treatment at $1173 \mathrm{~K}$ for $1.8 \mathrm{ks}$. Anisotropy in the shape recovery strain and Young's modulus was observed in both specimens heat treated at 873 and $1173 \mathrm{~K}$. For the specimen heat treated at $873 \mathrm{~K}$, a large recovery strain of $3.4 \%$ was observed when the loading axis is along the rolling direction (RD) and the transverse direction (TD). On the other hand, recovery strain took the largest value along the RD and the lowest value along the TD for the specimen heat treated at $1173 \mathrm{~K}$. The experimental results on orientation dependence of transformation strain were in good agreement with calculated results utilizing the texture information and lattice correspondence between martensite and parent phases. Kim et al [32] investigated the shape memory behavior of Ti-22Nb-(0.5-2.0)O(at.\%) alloys. The fracture stress of both as-rolled specimen and solution treated specimen increased with increasing oxygen content. A fracture stress of $1.37 \mathrm{GPa}$ was obtained in the as-rolled Ti-22Nb-2O (at.\%) alloy. The martensitic transformation temperature is decreased by $160 \mathrm{~K}$ per $1 \%$ increase of oxygen content. Superior shape memory effect and superelastic behavior were observed at room temperature in Ti-22 $\mathrm{Nb}-(0.5-1.5) \mathrm{O}($ at. $\%)$ alloys. The addition of oxygen stabilized superelastic behavior of $\mathrm{Ti}-\mathrm{Nb}$ alloys by increasing the critical stress for permanent deformation. The maximum shape recovery strain of $4.0 \%$ and the critical stress of $900 \mathrm{MPa}$ for permanent deformation were obtained in the Ti-22Nb-0.5O (at.\%) and Ti-22Nb-1.5O(at.\%) alloys, respectively. Xiong et al [33] investigated mechanical properties of porous Ti-26 (at.\%) Nb shape memory alloy fabricated by space-holder sintering process. The porous structures of the foams were characterized by scanning electron microscopy (SEM). The mechanical properties of the Ti-26(at.\%)Nb foam samples were investigated using compressive test. Results indicate that mechanical properties of Ti-26 (at.\%) $\mathrm{Nb}$ foam samples are influenced by foam porosity. The plateau stresses and elastic moduli of the foams under compression decrease with the increase of their porosities. The plateau stresses and elastic moduli are measured to be from 10 200 MPa and 0.4 5.0 GPa for the Ti-26 (at.\%) Nb foam samples with porosities ranged from 80 50\%, respectively. Kim et al [34] investigated the effect of Ta addition on shape memory behavior of Ti-22 at.\% $\mathrm{Nb}$ alloy. The shape memory effect with the maximum recovery strain of $2.7 \%$ was observed at room temperature in the Ti-22 (at.\%) $\mathrm{Nb}$ alloy. The martensitic transformation temperature of the Ti-22 (at.\%) $\mathrm{Nb}$ alloy decreased by $30 \mathrm{~K}$ per 1 at.\% addition of Ta. The superelastic strain increased with increasing Ta content. Almost perfect superelastic behavior was observed until $2 \%$ tensile strain in the Ti-22Nb-(6-8) (at.\%) Ta alloys. The apparent yield stress decreased with increasing Ta content reaching a minimum yield stress around 4 at.\%, and then the yield stress increased by further addition of Ta. The critical stress for slip increased with increasing Ta content. A higher critical stress for slip and a lower stress for inducing martensitic transformation resulted in a larger shape recovery strain above $3.0 \%$ in the Ti-22Nb-(4-6) Ta (at.\%) alloys. Wang et al [35] investigated the effect of Sn content on the microstructure, phase constitution and shape memory effect of Ti-Nb alloys. There exists the dislocation wall inside the single phase in the $\mathrm{Ti}-16 \mathrm{Nb}-5 \mathrm{Sn}$ (at.\%) alloy. The shape recovery ratio decreases with increasing the bending strain and the bending temperature, which is in correspondence with the different deformation mechanisms at different temperature ranges. The shape recovery ratio shows a decreasing trend with the increase of Sn content at the same bending strain and temperature. The maximum completely recovery strain is around 4\%. Takahashi et al [36] investigated the effect of heat treatment and Sn content on superelasticity in biocompatible TiNbSn alloys. Martensitic transformation temperature decreased rapidly with increasing Sn content. In-situ optical microscopic observation on cooling and heating indicates that the martensite is thermoelastic, corresponding to small temperature hysteresis between the martensitic and the reverse transformations, which is determined by differential scanning calorimetry. By controlling the heat 
treatment condition and $\mathrm{Sn}$ content, large superelastic strain is obtained at room temperature.

\section{Conclusions}

The shape memory property and superelasticity of $\mathrm{Ni}$-free $\mathrm{Ti}-\mathrm{Nb}$-based alloys have been widely studied and many results have been produced. $\mathrm{Nb}$ contents are focused on the ranges from 22 to 26 (at.\%), in which the Ti-Nb-based alloys possess $\alpha$ " and $\beta$ phases. The $\alpha " \leftrightarrow \beta$ thermoelastic transformation produces the shape memory effect and superelasticity. The additions of ternary elements such as $\mathrm{Al}, \mathrm{Si}, \mathrm{Ta}$ and so on, and optimal heat treatments can improve shape memory property and superelasticity of Ti-Nb-based alloys. Among the reported Ti-Nb alloys, Ti-22Nb-4Zr (at.\%) and $\mathrm{Ti}-24 \mathrm{Nb}-3 \mathrm{Al}$ (at.\%) possesses large recovery strain, whose value is $4.3 \%$ for the former alloy and $4.7 \%$ for the latter alloy.

\section{Acknowledgements}

This work is sponsored by Qing Lan Project of Jiangsu and supported by Research Foundation of Suzhou Vocation University (2013SZDYJ05).

\section{References}

[1] T.W.Duerig, J. Albrecht, D. Richter, P. Fischer, Acta Metall. 30(1982)2161-2172.

[2] T. Grosdidier, M. J. Philippe, Mater Sci Eng A. 291(2000) 218-223.

[3]E.Takahashi, T. Sakurai, S. Watanabe, N. Masahashi, S. Hanada, Mater Trans. 43(2002) 2978-2983.

[4] T. Maeshima, M. Nishida, Mater Trans. 45(2004)1096-1100.

[5]T. Zhou, M. Aindow, S. P. Alpay, M. J. Blackburn, M. H.Wu, Scripta Mater. 50(2004)343-348.

[6]Y. Fukui, T. Inamura, H. Hosoda, K. Wakashima, S. Miyazaki, Mater Trans. 45(2004)1077-1082.

[7]H. Y. Kim, Y. Ohmatsu, J. I. Kim,H. Hosoda, S. Miyazaki, Mater Trans.45(2004)1090-1095.

[8]T. Maeshima, S. Ushimaru, K. Yamauchi, M. Nishida, Mater. Sci. Eng. A.430-438(2006)844-847.

[9] T. Maeshima, M. Nishida, Mater Trans. 45(2004)1101-1105.

[10] H. Y. Kim, Y. Ohmatsu, J. I. Kim,H. Hosoda, S. Miyazaki, Mater Trans.47(2006)518-522.

[11] S. Miyazaki, H. Y. Kim, H. Hosoda, Mater Sci Eng A. 438(2006)18-24.

[12] H. Y. Kim, S. Hashimoto, J. I. Kim, H. Hosoda, S. Miyazaki. Mater Trans. 45(2004)2443-2448.

[13] H. Y. Kim, Y. Ikehara, J. I. Kim, H. Hosoda, S. Miyazaki, Acta Mater.54(2006)2419-2429.

[14] H. Matsumoto, S. Watanabe, S. Hanada, Mater Trans. 46(2005)1070-1078.

[15]T. Inamura, Y. Fukui, H. Hosoda, K. Wakashima, S. Miyazaki, Mater. Sci. Eng. C. 25(2005)426-432.

[16] M. Ikeda, Y. Nakamura, N. Takahama, J Jpn Inst Metals. 67(2003)420-423.

[17]M. Ikeda, S. Y. Komatsu, Y. Nakamura, Mater Trans. 45(2004)1106-1112.

[18]T. Peradze, I. Stamateli, J. Cederstrom, T. Berikashvili, A. Razov, K. Gorga, Int J Appl Electromagnet Mech.23(2006)39-43.

[19] P. J. S. Buenconsejo, H. Y. Kim, H. Hosoda, S. Miyazaki, Acta Mater. 57(2009)1068-1077.

[20] C. Baker, Mater. Sci. J. 5(1971)92-100.

[21] M. Tahara, H. Y. Kim, H. Hosoda, S. Miyazaki, Acta Mater. 57(2009)2461-2469.

[22] Kim H S, Kim W Y, Lim S H, Scripta Mater.54(2006)887-891. 
[23] D. H. Ping, Y. Mitarai, Y. X. Yin, Scripta Mater. 52(2005)1287-1291.

[24]Y. L. Hao, S. J. Li, S. Y. Sun, R. Yang, Mater. Sci. Eng A. 441(2006)112-118.

[25]H. Y. Kim, J. I. Kim, T. Inamura, H. Hosoda, S. Miyazaki, Mater. Sci. Eng. A. 438-440(2006)839-843.

[26] J. I. Kim, H. Y. Kim, T. Inamura, H. Hosoda, S. Miyazaki, Mater. Sci. Eng. A. 403(2005)334-339.

[27] C. M. Lee, C. P. Ju, J. H. Chern Lin, Journal of Oral Rehabilitation. 29(2002)314-322.

[28] Y. Mantani, M. Tajima, Mater. Sci. Eng. A. 442(2006)409-413.

[29] L. A. Matlakhova, A. N. Matlakhov, S. N. Monteiro, S. G. Fedotov, Revista Materia.11(2006)41-47.

[30] Y. W. Chai, H. Y. Kim, H. Hosoda, S. Miyazaki, Acta Mater. 57(2009)4054-4064.

[31] H.Y. Kim, T. Sasaki, K. Okutsu, J.I. Kim, T. Inamura, H. Hosoda, S. Miyazaki, Acta Mater. 54 (2006) 423-433.

[32] J. I. Kim, H. Y. Kim, H. Hosoda, S. Miyazaki, Materials Transactions. 46(2005)852-857.

[33] J. Y. Xiong, Y. C. Li, Y. Yamada, P. Hodgson, C. E. Wen, Materials Science Forum. 561-565 (2007)1689-1692.

[34] H. Y. Kim, S. Hashimoto, J. I. Kim, T. Inamura, H. Hosoda, S. Miyazaki, Mater. Sci. Eng. A .417(2006)120-128.

[35] B. L. Wang, Y. F. Zheng, L. C. Zhao, Mater. Sci. Eng. A. 486(2008)146-151.

[36]E.Takahashi, T. Sakurai, S. Watanab, N. Masahashi, S. Hanada, Mater.Trans.43(2002) 2978-2983. 